\title{
Space Vector Modulation of Nine Switch Inverter for Six Phase Induction Motor Drive
}

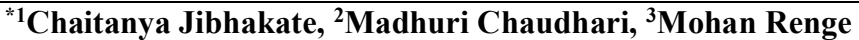 \\ ${ }^{1,2}$ Visvesvaraya National Institute of Technology, Nagpur \\ ${ }^{3}$ Shri Ramdeobaba College of Engineering and Management, Nagpur \\ Email: chaitanya.n.jibhakate@gmail.com,machaudhari@eee.vnit.ac.in,rengemm@rknec.edu
}

Received: 20th November 2019, Accepted: 31st January 2020, Published: 30th April 2020

\begin{abstract}
Induction motors are still popular in industries amongst the several types of motor due to its simple, robust and maintenance free construction. With the fast progress in transport industry the need exists for ac machines with higher power per unit. Six phase induction motor is a solution where higher power per volume is required such as for electric vehicle application. In this paper, six phase induction motor is operated by compact nine switch inverter. Space vector modulation technique is incorporated to operate nine switch inverter for six phase induction motor drive.
\end{abstract}

Keywords

Six Phase Induction Motor, Nine Switch Inverter, Space Vector.

\section{Introduction}

Induction motors are popular as they are cheaper, highly efficient, requires less maintenance, and robust construction as compare to other motor in a same segment. Although three phase induction motor are popular among there segment, high starting torque and higher power per volume may limit the application of this motor. In the application of electric vehicle it required higher power per volume. For these type of application increasing number of phases of induction motor results in increasing power density of motor retaining the advantages of the induction motor. Thus, six phase induction motor is a solution of higher power per volume application [1-3].

As the number of phases increases, required inverter switch count increases leading to high cost converter. For three phase induction three phase voltage source inverter is sufficient. As the phase increases from three to six, it requires twelve switch inverter to operate six phase induction motor. In this paper only nine switch inverter is developed to operate six phase induction motor.

The nine switch converter can be used as ac-dc-ac, dc-ac-ac, and ac-dc-dc depending upon its input and output connection. The nine switch converter is used as ac-dc-ac for various applications like reactive power compensation with induction motor drive, uninterrupted power supply etc. The nine switch converter with acdc-ac operation is explained with constant and variable frequency mode operation is explained in [4]. The efficient operation of the nine switch converter with ac-ac and dc-ac mode is explained in [5]. The pulse width modulation is explained in $[6,7]$ to increase efficiency of the nine switch converter. The reactive power compensation with induction motor drive under change in load condition is reported in [8].

\section{Methodology}

In this paper, six phase induction motor is modelled and operated from reduced nine switch inverter. The space vector pulse width modulation is used to operate nine switch inverter.

Fig. 1 show conventional six phase inverter. It requires 12 active switches for six phase output. Fig. 2 shows nine switch inverter which requires only nine switches thereby reducing a switch count by $25 \%$ compared to conventional 12 switch inverter. 


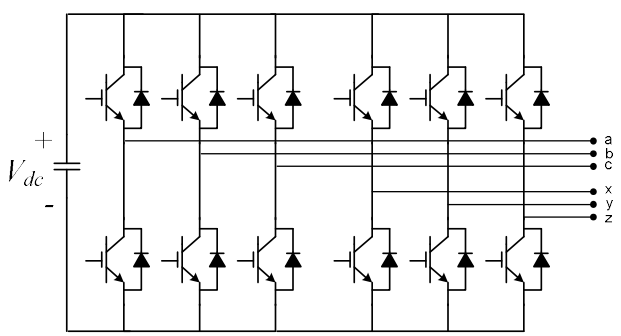

Fig. 1: Conventional Six Phase Inverter

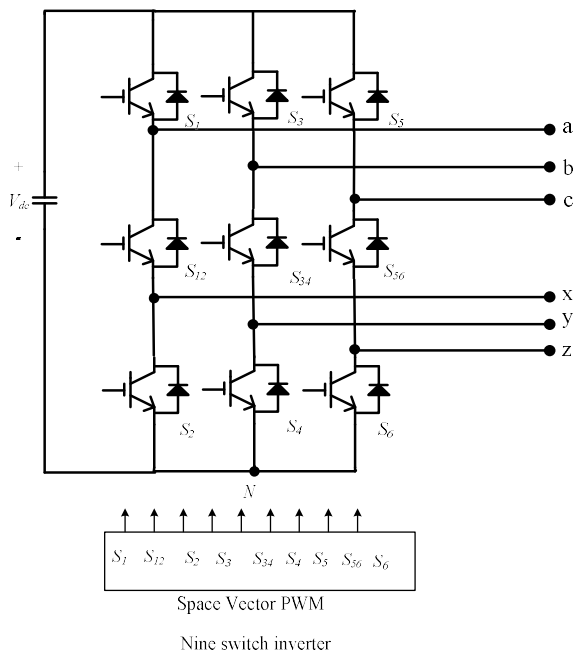

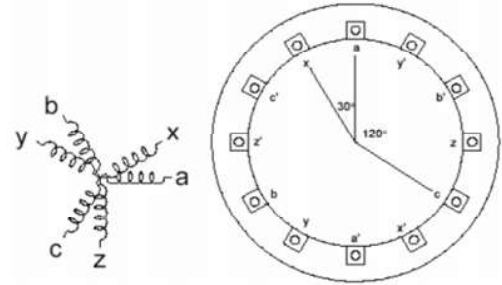

Basic Construction of six phase induction machine

Fig. 2: Nine Switch Inverter with Six Phase Machine Construction

\section{Operation of Six Phase Induction Motor and Nine Switch Inverter}

In the six phase induction motor, there are two sets of phases; phases 'abc' and phases 'xyz'. As shown in Fig. 2 , basic construction of six phase induction machine is presented. The phases 'abc' and 'xyz' are $120^{\circ}$ phase shifted within them and have $30^{\circ}$ phase with respect to each other. The number of winding turns of both the set of phases is same. The fault tolerance features of multiphase machine are one of the important advantages for the locomotive application.

\section{Nine Switch Converter}

The nine switch inverter with six phase output connected to the induction motor and gate logic controller is shown in Fig. 2. The nine switch inverter is operated as dc to ac converter. All the nine switches are operated in two inverter modes 'abc' and 'xyz' simultaneously. The group of upper six switches $\left(\mathrm{S}_{1}, \mathrm{~S}_{12}, \mathrm{~S}_{3}, \mathrm{~S}_{34}, \mathrm{~S}_{5}, \mathrm{~S}_{56}\right)$ operated as 'abc' inverter and group of lower six switches $\left(\mathrm{S}_{12}, \mathrm{~S}_{2}, \mathrm{~S}_{23}, \mathrm{~S}_{3}, \mathrm{~S}_{56}, \mathrm{~S}_{6}\right)$ operated as 'xyz' inverter. When NSC is operated as 'abc', upper group switches are active and rest of the lower three switches are ON. During NSC as 'xyz' inverter, lower group switches are active and rest of the upper three switches are ON. Middle three switches $\left(\mathrm{S}_{12}, \mathrm{~S}_{34}, \mathrm{~S}_{56}\right)$ are active in both inverter operation.

\section{Modulating Reference Generation}

For generating desired gate pulses reference is generated using following equation:

$$
\begin{aligned}
& v_{a b c}=m_{a b c} \sin [(2 \times \pi \times f \times t)]+V_{d c_{-} o f f s e t} \\
& v_{x y z}=m_{x y z} \sin [(2 \times \pi \times f \times t)+\delta\rfloor+V_{d c_{-} \text {offset }}
\end{aligned}
$$

where, $m_{a b c}$ and $m_{x y z}$ are the modulation index, $\delta=30^{\circ}$ and $V_{d c \_o f f s e t}=0.5$. The dc-offset is added for the satisfactory operation of nine switch converter [9]. The $v_{a b c}$ are the three modulating reference shifted by $120^{\circ}$. Similarly, $v_{x y z}$ are the three modulating reference shifted by $120^{\circ}$.

The control logic is as shown in fig 3. The detail dwell tie calculation is explained in [10-11]. The generated references are shown in fig 4. 


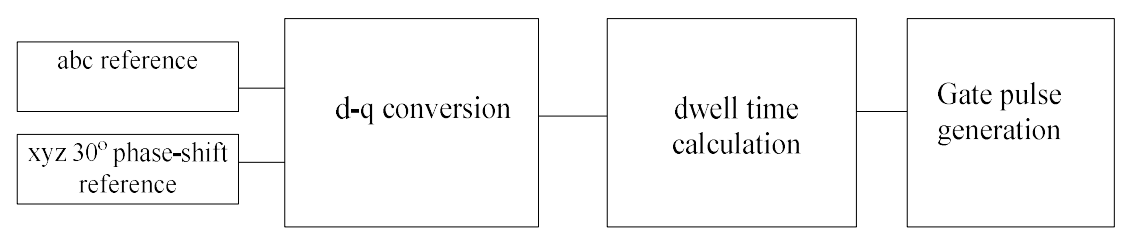

Fig. 3: Space Vector PWM Logic.
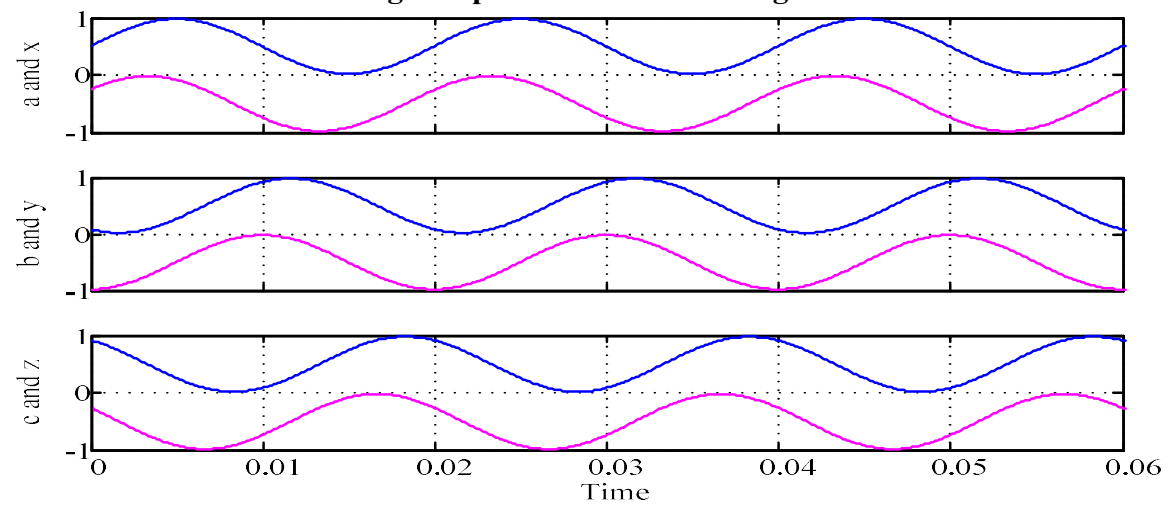

Fig. 4: Modulating References for Six Phase Output.

\section{Result and Discussion}

The six phase induction motor is modelled for $3 \mathrm{HP}, 50 \mathrm{~Hz}, 200$ volts, 4 pole, star connected. Fig. 5 shows, six phase output phase voltage of the nine switch inverter. The phase voltages 'abc' are 120o phase shifted and phase voltages 'xyz' are also $120 \mathrm{o}$ phase shifted with respect to each other. The 'xyz' phase voltages are $30 \mathrm{o}$ leading to 'abc' phase voltages. Fig. 6 shows six phase induction motor output current. Fig. 7 shows speed of the induction motor.
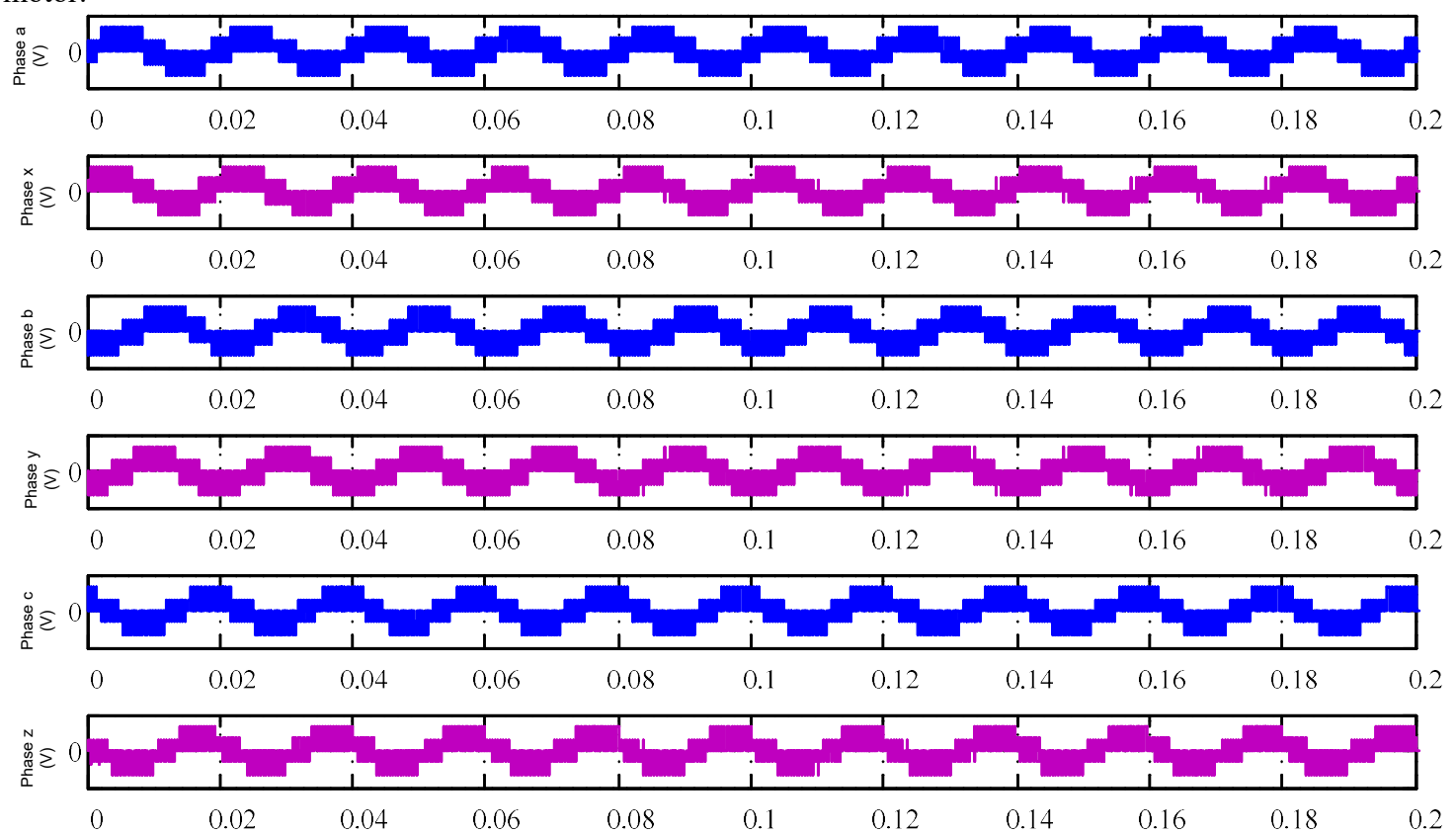

Fig. 5: Six Phase Output Phase Voltage. $V_{p h}$ 'abc' and $V_{p h}$ 'xyz' $\left\llcorner 30^{\circ}\right.$ 


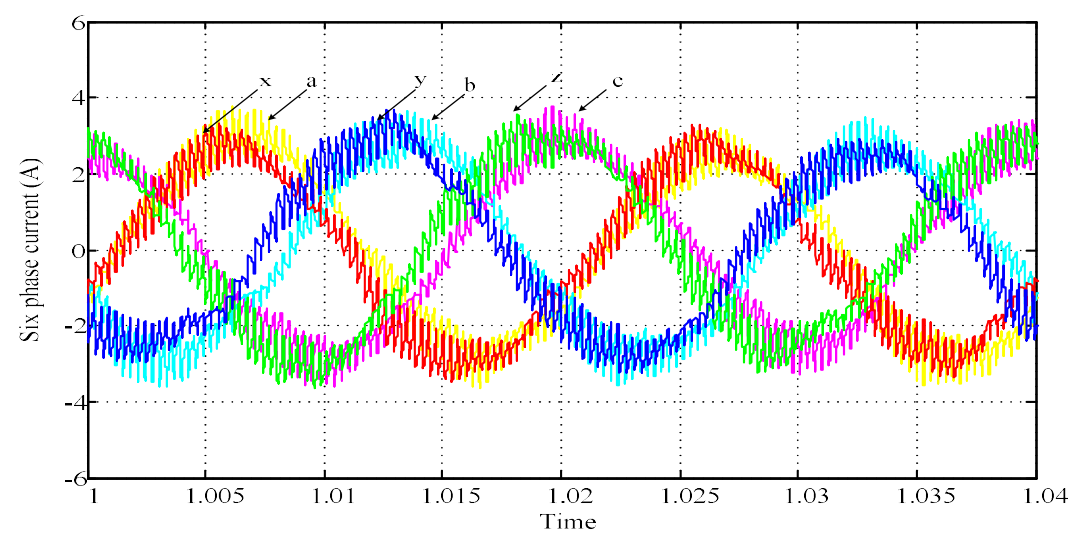

Fig. 6: Six Phase Output Phase Current

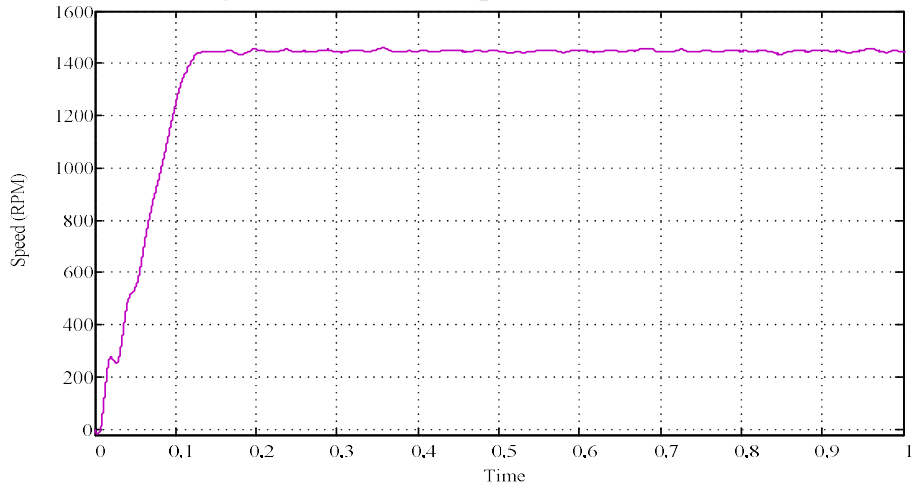

Fig. 7: Speed of Six Phase Induction Motor

\section{Conclusion}

In this paper, six phase induction motor is operated by compact nine switch inverter. The use of nine switch inverter reduces switch count by $25 \%$ compared to the conventional 12 switch six phase inverter. Space vector modulation technique is incorporated to operate nine switch inverter for six phase induction motor drive. Six phase induction motor is a solution where higher power per volume is required such as for electric vehicle application.

\section{References}

1. J. Listwan and K. Pienkowski, "Experimental Studies of DTC-SVM Control of Six-Phase Induction Motor with Application of the Super-Twisting Sliding Mode Controllers," 2018 International Symposium on Electrical Machines (SME), Andrychów, 2018, pp. 1-6

2. P. S. Dainez and E. Bim, "Implementation details of an adaptive control by a b-spline neural network applied to an asymmetric six-phase induction motor," 2017 Brazilian Power Electronics Conference (COBEP), Juiz de Fora, 2017, pp. 1-7.

3. A. A. Elserougi, A. S. Abdel-Khalik, A. M. Massoud and S. Ahmed, "An asymmetrical six-phase induction motor drive based on nine-arm Modular Multilevel Converter (9AMMC) with circulating current suppression," 2015 4th International Conference on Electric Power and Energy Conversion Systems (EPECS), Sharjah, 2015, pp. 1-6.

4. Congwei Liu, BinWu, Navid R. Zargari, Dewei (David) Xu, and Jiacheng Wang, "A Novel Three-Phase ThreeLeg AC/AC Converter Using Nine IGBTs", IEEE Trans. Power Electron., vol. 24, no. 5, pp.1151-1160, May. 2009

5. Zian Qin, Poh Chiang Loh, and Frede Blaabjerg, "Application Criteria for Nine-Switch Power Conversion Systems with Improved Thermal Performance," IEEE Trans. Power Electron., vol. 30, no. 8, pp.4608-4620, Aug.2015

6. Feng Gao, Lei Zhang, Ding Li, Poh Chiang Loh, Yi Tang, and Houlei Gao, "Optimal Pulsewidth Modulation of Nine-Switch Converter", IEEE Trans. Power Electron., vol. 25, no. 9, pp.2331-2343, Sep.2015

7. Seyed Mohammad Dehghan Dehnavi, Mustafa Mohamadian, Ali Yazdian, and Farhad Ashrafzadeh, "Space Vectors Modulation for Nine-Switch Converters", IEEE Trans. Power Electron., vol. 25, no. 6, pp.1488-1496, June 2010 
8. Chaitanya N. Jibhakate, Madhuri A. Chaudhari and Mohan M. Renge, "Power Factor Improvement Using Nine Switch AC-DC-AC Converter", in Power Systems (ICPS), 2016 IEEE 6th International Conference, Mar. 4-6, 2016, pp. 1-4.

9. S. M. Dehghan, M. Mohamadian, A. Yazdian and F. Ashrafzadeh, "A novel space vector modulation for nine-switch converters," 2009 IEEE Energy Conversion Congress and Exposition, San Jose, CA, 2009, pp. 885891.

10. S. M. Dehghan, M. Mohamadian and M. A. E. Andersen, "Full space vectors modulation for nine-switch converters including CF \& DF modes," 2010 4th International Power Engineering and Optimization Conference (PEOCO), Shah Alam, 2010, pp. 89-94.

11. M. E. Ahmed and S. Mekhilef, "Three-phase three-level nine switches inverter employing space vector modulation," 2008 12th International Middle-East Power System Conference, Aswan, 2008, pp. 341-347. 